\title{
Classification of Regions by Climatic Characteristics for the Use of Renewable Energy Sources
}

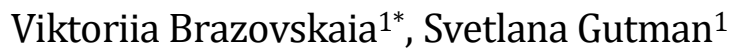 \\ ${ }^{1}$ Peter the Great St. Petersburg Polytechnic University, Politehnicheskaya Street 29, Saint Petersburg, 195251, \\ Russia
}

\begin{abstract}
The transition from fossil fuels to "green" energy involves increasing energy efficiency from existing energy systems and reducing harmful emissions into the atmosphere. Currently, renewable energy sources (RESs) are a priority way of generating energy for Smart Grid systems that meet the requirements of efficiency and safety. Classification of regions by similar climatic characteristics helps as an effective tool for avoiding various risks when implementing a Smart Grid based on RES. In this paper, the clustering method is considered by the authors as a tool to achieve the goal of the study: the division of regions into clusters with similar climatic characteristics, which will allow to choose the most efficient RES for each specific region. The authors considered the selected climatic characteristics based on certain factors after a review of existing sources, for example, the level of solar insolation, average annual wind speed, average annual temperature, and average annual precipitation for 84 subjects of the Russian Federation. As a result, five clusters were identified by the $k$-means method using the Stata software. For each cluster, the characteristics and the most preferred type of RES for the implementation of Smart Grid are described. Cluster analysis based on climatic characteristics is the first stage of a comprehensive methodology for selecting the most favorable regions for the development of both a particular type of RES and Smart Grid systems in general, as proposed by the authors.
\end{abstract}

Keywords: Climate-related risks; Clustering analysis; Efficiency; Renewable energy; Smart grid

\section{Introduction}

The energy sector is one of the key sectors in the economy of any country. The energy sector ensures the uninterrupted operations of the entire industrial complex and enables the population to use electricity and heat for household needs every day; therefore, its development is an important task of public administration. In recent years, the topic of introducing "smart" technologies into the energy system has been widely discussed. These technologies would not only reduce the costs of electricity production but also help to control consumption, reduce losses in networks, and therefore reduce the risks of implementing Smart Grid projects. In addition, global trends indicate the need to switch from traditional energy to cleaner energy sources to reduce harmful emissions (Kusrini et al., 2017; Tishkov et al., 2020).

The relevance of the work is due to the growing interest in the issue of intellectualization of the electric power industry as well as the development of digital

*Corresponding author's email: brazovskaya_vv@spbstu.ru, Tel.: +7-812-534-73-31

doi: 10.14716/ijtech.v12i7.5339 
technologies in general. In addition, the requirements for reliability, quality, and environmental friendliness of the electricity produced are constantly growing, which is the driving force behind the development of modern technologies in this industry and the implementation of renewable energy sources (RES) into the country's energy system.

The purpose of this work is to develop a map of the use of renewable energy in the regions of the Russian Federation when implementing Smart Grid in order to reduce climate risks. In this regard, it is necessary to determine for which regions it is advisable to introduce such a system as well as to determine the risks of implementing a Smart Grid based on RES.

The United States and the European Union (EU) countries were the first to introduce the Smart Grid concept. They initiated the introduction of smart grids as one of the objectives of the energy and innovation development strategy. Currently, China is the leader in the investment and implementation of Smart Grids, which will become an effective tool to increase the volume of wind and solar energy there to cover the growing energy consumption, especially for remote areas (Lui and Van, 2019).

When analyzing publicly available sources, six main advantages of Smart Grid were identified: (1) reliability, which had made it possible to reduce the cost of power outages and quality violations, in addition to reducing the likelihood of occurrence and consequences of widespread outages (Dorofeeva et al., 2019); (2) saving-lower electricity prices compared to classical networks as well as the creation of new jobs; (3) efficiencywith the integration of renewable and alternative energy sources, it becomes possible to reduce the cost of production, delivery, and consumption of electricity; (4) environmental friendliness - global climate change encourages the use of RESs. This will reduce emissions compared to public energy networks and increase the efficiency of energy production, delivery, and consumption (Khalil et al., 2019); (5) protection, which is achieved by reducing the likelihood and consequences of man-made accidents and natural disasters (Bugaeva et al., 2020); (6) safety, which is achieved by reducing the risks inherent in the electrical system as well as reducing the exposure time to these hazards (Lukyanchenko, 2017).

The concept of using Smart Grids together with RESs is more often considered these days (Prakesh et al., 2017) and the use of solar panels (on photovoltaic cells) and wind generators is becoming more widespread every year. Power electronics, according to the authors, is the most important element of modern Smart Grids and renewable energy systems. This paper also discusses modern power semiconductor devices and the use of power electronics in energy saving, electric vehicles, renewable energy systems and grid energy storage, and Smart Grid elements.

RESs together with energy storage systems represent the solution to the main problems of the modern energy system, which are related to the need to improve reliability, environmental friendliness, etc. Such systems embedded in Smart Grids are able to solve the problem of power outages (Baza et al., 2019). Moreover, much attention is being paid to the modernization of storage systems to improve the properties of reliability and continuity, and, therefore, the quality of energy supply (Quan et al., 2019). A partial transition to RESs will help to stop the growth of harmful emissions into the atmosphere and increase the environmental friendliness of the energy produced (Jebli et al., 2020).

When compiling these projects, you should pay attention not only to the financial payback but also to how the selected systems are suitable in each case. Each project is individual, hence it is necessary to take into account the peculiarities of the climate and consumer preferences. In addition, there is an increase in the stability of the power system with more implementation of such projects, that is, an increase in the ability of the system 
to reduce the likelihood of power outages (Khalid and Javaid, 2020).

Managing such projects always comes with a lot of risks. Despite the possibility of reducing energy consumption costs when implementing energy efficiency requirements in projects, the cost of the project itself increases significantly, which affects the payback of such projects (Setiawan and Asvial, 2016; Mansouri et al., 2021). It is also noted that the digitalization of home systems puts personal data at risk. In addition, there are concerns that it will make it the collection of personal data easier that may get to third parties, thanks to the introduction of intelligent networks (Attia, 2019). The risks associated with the scale of such projects as well as organizational and financial risks are separately noted (Gasho et al., 2020; Olifirov et al., 2019).

The implementation of new technologies, such as Smart Grid, is accompanied by technological risks. First, the entire power system must be prepared, which means that modernization of all fixed assets, replacement of outdated equipment, and comprehensive IT equipment is required. It is also necessary to establish the production of modern equipment, reequipment of production lines, etc., in order to reduce risks when importing equipment from other countries (Ourahou et al., 2020).

In order to achieve the maximum environmental effect in reducing harmful emissions into the atmosphere from the introduction of Smart Grid, RESs are integrated into this technology as energy generators. RES and energy storage systems are the key technologies for smart grids and provide ample opportunities for decarbonization of urban areas, frequency regulation, voltage deviations, and rapid response to peak ratings when the demand exceeds production (Guenther, 2018; Worighi et al., 2019).

The implementation of renewable energy requires not only reforming the electricity market but also taking into account the peculiarities of climatic characteristics (dependence of output on external environmental conditions) in order to reduce climate risks. The efficiency of solar panels is associated with the level of solar insolation, and energy sources based on wind turbines are associated with the average annual wind speed (Pereverzeva et al., 2020). Finding renewable energy-based stations in an open space creates the need to keep in mind the amount of precipitation (Abdelkareem et al., 2018). In their project, Kalogirou et al. (2013) considered the maximum and minimum average annual temperature as climatic characteristics. In order to enhance the service life of such stations as well as the efficiency of generation and reduce the payback period of Smart Grid projects, it is necessary to competently approach the analysis of each specific territory according to these climatic characteristics. Therefore, it was decided to consider the cluster analysis method as the basis for making a decision on choosing the type of renewable energy for each individual region.

\section{Methods}

\subsection{Research Methodology}

In order to overcome the climate risk of introducing Smart Grid based on renewable sources, within the framework of this study, it is proposed to conduct a cluster analysis by region based on climatic indicators that most strongly affect the efficiency of generation using RESs.

The classification was carried out on the basis of multidimensional statistical analysis (cluster analysis). The implementation of this method includes the following tasks (Nasledov, 2013):

1. Selection of the classification method (clustering).

2. Determination of the composition of the used features of objects.

3. Choice of the method of measuring the distance between objects. 
4. Determination of the number of clusters.

5. Presentation and interpretation of classification results.

The latest data on solar insolation, kilowatt-hours per square meter $\left(\mathrm{kWh} / \mathrm{m}^{2}\right)$; wind speed, meters per second (m/s); average annual temperature, degrees; average annual precipitation $(\mathrm{mm})$ were collected from open sources in all regions of the Russian Federation. According to these climatic characteristics, the regions of the Russian Federation were further divided into clusters depending on climate characteristics.

The choice of clustering method depends on the structure of the clusters under study. In these calculations, the $k$-means method is used, which belongs to the group of iterative methods of the reference type. The $k$-means method requires a preliminary decision on the number of clusters, which allows forming clusters in which there will be the most similar regions according to climatic characteristics.

To determine the optimal number of clusters, "hierarchical cluster analysis" was used and the results obtained in the "Coefficients" column of the "Agglomeration Steps" table in were analyzed. The coefficients obtained reflect the distance between the two clusters calculated based on the selected distance measure (Euclidean distance). The optimal number of clusters in our study turned out to be 5 , which is equal to the difference between the number of observations (84) and the step number (79), after which the coefficient increases abruptly.

For visual analysis of the obtained distribution of regions, scattering diagrams, histograms, and tree-like dendrograms were constructed.

To carry out cluster analysis by climatic characteristics, the software used for statistics and data processing was Stata, and the analysis was carried out using the $k$-means method.

\subsection{Size of Dataset}

The authors took the 84 main subjects of the Russian Federation for the analysis. Descriptive statistics are presented in Table 1.

Table 1 Descriptive statistic

\begin{tabular}{lccccc}
\hline \multicolumn{1}{c}{ Variable } & Obs. & Mean & Std. Dev. & Min & Max \\
\hline Sun Insolation, $\mathrm{kWh} / \mathrm{m}^{2}$ & 84 & 3.721548 & 0.4404338 & 2.62 & 4.65 \\
Wind velocity, m/s & 84 & 3.515357 & 0.5763312 & 2.86 & 5.6 \\
$\begin{array}{l}\text { Average yearly temperature, } \\
\text { degrees }\end{array}$ & 84 & 3.902381 & 4.27861 & -8.8 & 14.2 \\
Average an. precipitation, $\mathrm{mm}$ & 84 & 553.131 & 143.7498 & 233 & 987 \\
\hline
\end{tabular}

Descriptive statistics is needed for data processing, systematization, and visual presentation in the form of a table as well as for quantitative description of data by means of basic statistical indicators. Descriptive statistics showed that there were no missing values in the dataset. In addition, in the future, the minimum and maximum values as well as the standard deviation will help in the description of clusters.

\section{Results and Discussion}

\subsection{Cluster Analysis}

Based on the literature review, the climatic characteristics that are most relevant for the selection of RES, which is used in the implementation of Smart Grid, were determined. For the use of solar panels, it is necessary to know the average level of annual solar insolation in the region, and for the use of wind generators as an energy source, the average annual wind speed in a given area. In addition, the average annual temperature and average precipitation have an impact on the use of renewable energy. 
For the initial definition of cluster groups, scattering diagrams were constructed, allowing to establish dependencies on the graphical representation without mathematical data processing. (Figure 1).

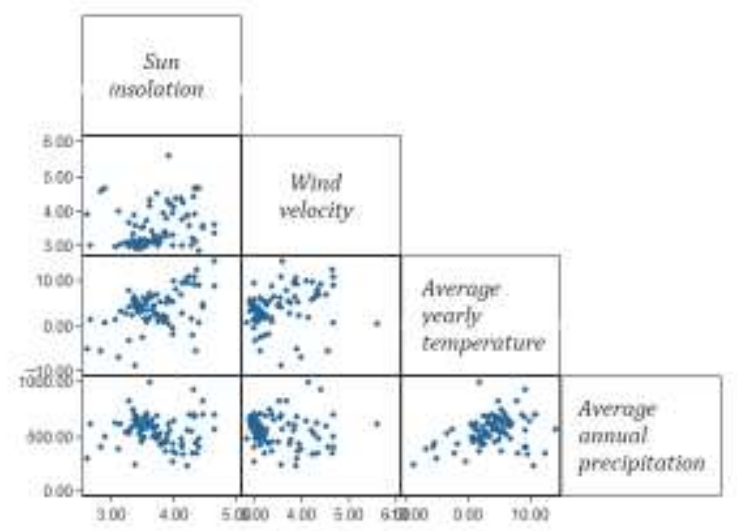

Figure 1 Scattering diagram

In this case, with a sufficiently large amount of data and criteria, we will not be able to explicitly determine the number of clusters.

As mentioned in the previous paragraph, the optimal number of clusters for this study was determined, and it was equal to 5 . This number of clusters was specified during the cluster analysis as was done by the Stata software package.

When constructing the dendrogram, the allocation of 5 clusters is clearly traced (Figure $2 \mathrm{a})$, and while grouping 84 subjects into 10 enlarged groups, 5 clusters became clearly visible (Figure $2 b$ ).

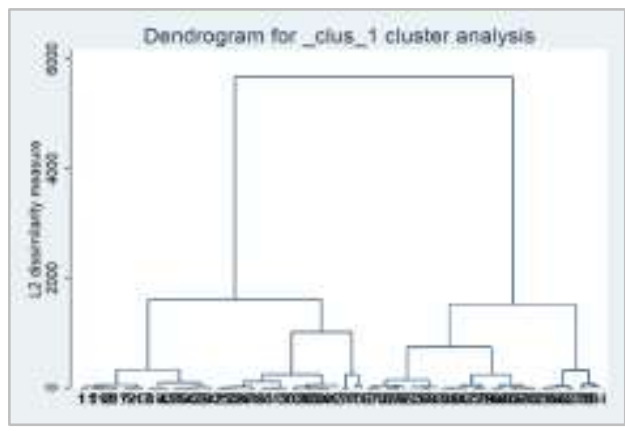

(a)

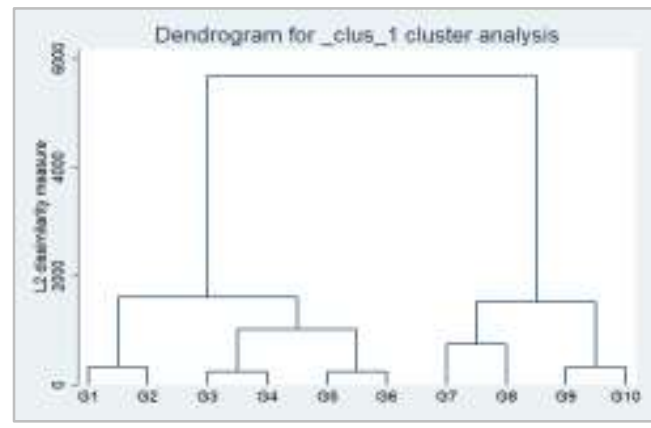

(b)

Figure 2 Dendrogram: (a) by all regions; (b) by groups of regions

Thus, the graphical interpretation confirmed that the calculated number of clusters equal to five can be accepted.

In the next paragraph, each cluster and its characteristics will be discussed in detail.

\subsection{Analysis of the Resulting Clusters}

The results of cluster analysis are shown in Figure 3. The map shows all the regions as well as the number of clusters to which the regions belong.

Cluster 1: In these regions, all parameters were set at the average values. When implementing Smart Grid based on the RES, preference should be given to projects with combined sources of energy generation (sun + wind), which will be much more profitable than the sun or wind separately. It is also possible to combine with diesel- or gas-powered electrical installations to cover peak loads. Such a system of solar panels plus wind generators is designed to ensure that in the absence of one or both energy sources, the 
supply of electricity does not stop.

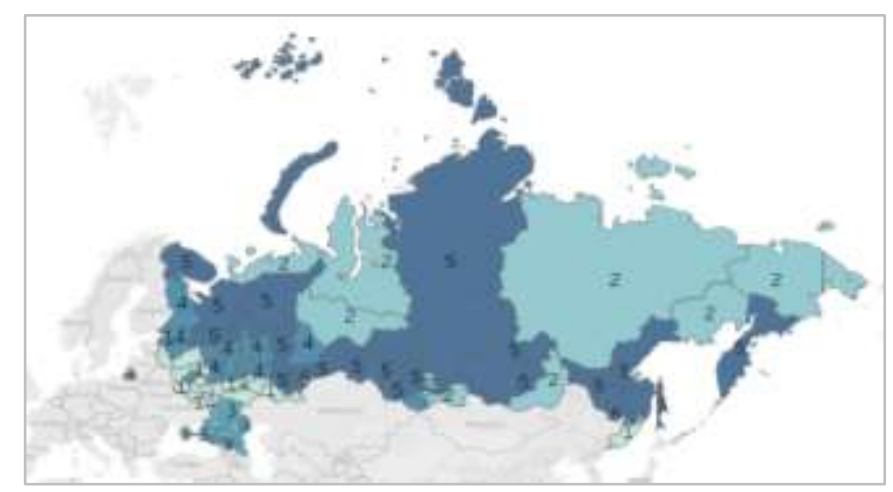

Figure 3 Distribution of regions by clusters

When there is no wind or sun, electricity is supplied from batteries, and in case the charge runs out, a backup connection is usually made to a generator or a centralized source. In this case, the batteries take charge again, and hence consumers are provided with electricity. Hybrid power plants have the prospect of being used only in areas where solar and wind potentials are high enough (as in the regions of this cluster).

Cluster 2: There is practically no hot weather in these regions, because the average annual temperature is at the minimum level. The regions vary in the level of solar insolation, from low to medium (on average from 2.7 to 3.4). According to the wind speed, the regions can be considered quite windy, but due to extremely low temperatures, the implementation of a Smart Grid based on renewable energy will be distinguished by a high cost. In addition, it is necessary to select materials that would be resistant to extremely low temperatures. Wind is considered a priority, since there are already special liquids with an operating temperature of -60 Celsius degrees, which serve to safely remove ice from the blades and housings of wind turbines without causing mechanical and chemical damage to them. The use of such liquids carries additional costs, but they can be used in areas with extremely low temperatures.

Cluster 3: A mild climate with hot summers and noncold winters (the average annual temperature has stopped at a level close to the maximum) as well as a high level of solar insolation make these regions attractive for the implementation of Smart Grid with renewable energy based on solar panels, for the operation of which the presence of sunlight is important. For the production of hot water in these regions, it is possible to install solar collectors, since in warm, year-round weather, the collector will not give off much heat.

Also, the average annual wind speed, which is at the level of average values (3-3.5 m/s and above), makes it possible to implement projects with combined sources of electricity generation (sun and wind). With the weakening of the wind force, the solar panels will not allow the energy production to stop in the daytime. This will allow you to use smallercapacity batteries.

Cluster 4: The level of solar insolation is much higher than the average values at a low average annual wind speed. The average temperature for the year is no more than 5 degrees, and there is also a large amount of precipitation. In these regions, it is possible to implement Smart Grid projects based on RESs, but equipment that is more resistant to low temperatures and large amounts of precipitation will be required, which would allow efficient conversion of solar energy. It will also be possible to use only photo converters, for which light is important, not heat, as with flat collectors.

Cluster 5: These regions are characterized by a low level of average annual temperature. Solar insolation and wind speed are strikingly different; there are both 
regions with a high level of insolation and high wind speed, and vice versa. The regions also vary in terms of precipitation: from average $(350 \mathrm{~mm})$ to large (800 $\mathrm{mm}$ and above) precipitation per year. In such regions, the cost of implementing Smart Grid projects based on RESs will be quite high due to the required, more detailed analysis of all factors as well as consideration of the characteristics of each region separately. This cluster collected all ambiguous regions in terms of climatic characteristics, for which it was impossible to unambiguously determine the type of renewable source that could be used as efficiently as possible.

Among the existing studies, there are different criteria for choosing a country or region for the implementation of Smart Grid based on RESs. Roques et al. (2010) single out RES support measures as a fundamental factor for the development of this type of energy. Gasho et al. (2020) identify economic, technological, and organizational factors as the key problems of the introduction and distribution of renewable energy.

Depending on the climatic characteristics, various technologies are used to generate energy. Roques et al. (2010), by using the example of wind farms, show that their geographical diversification can smooth out fluctuations in energy production and reduce the associated costs of balancing and system reliability when implementing Smart Grid systems.

Engeland et al. (2017) indicate that by studying the parameters of solar radiation, wind speed, and temperature, it is possible to determine the balance between solar and wind energy as well as energy demand, which will increase the attractiveness of SG projects based on RES. In this regard, it can be argued that cluster analysis by climatic characteristics is necessary at the initial stage.

As a further direction of research, the authors propose to explore the possibility of compiling a methodology to determine the most suitable regions for the effective implementation of smart grids based on RESs (Figure 4). It is necessary to analyze the components of each stage, which will allow you to make the most detailed map.

It is worth noting that this sequence of actions is suitable not only for the analysis of regions but also for small countries whose territories do not differ much in climatic, economic, and other characteristics.

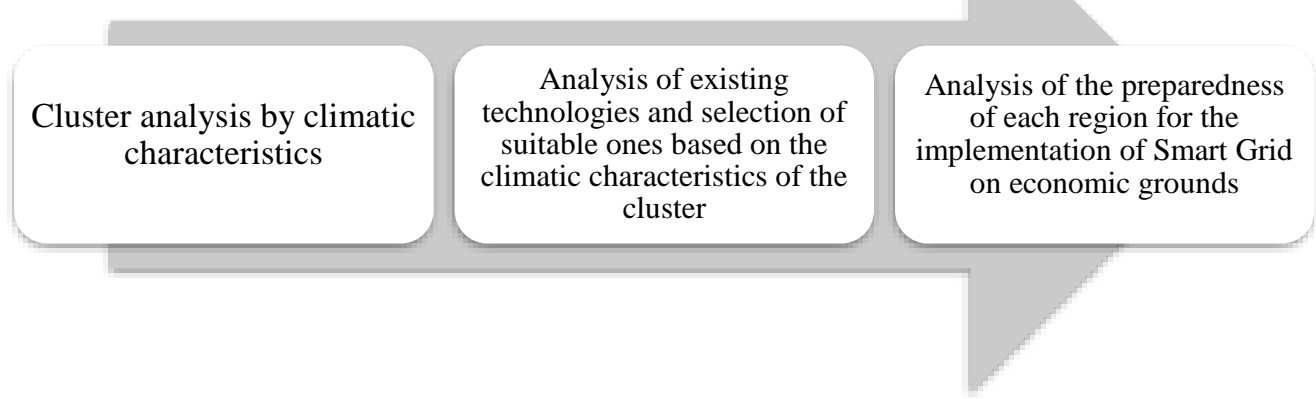

Figure 4 Methodology for determining regions for the implementation of integrated Smart Grid systems

Further consideration of the following stages will allow us to obtain a comprehensive methodology for the most effective implementation of Smart Grid systems without the global costs of upgrading the existing grid.

\section{Conclusions}

The introduction of smart grids based on RESs needs to be developed in our country to 
improve the quality of the energy system. When reviewing the works of other authors, it was revealed that with an increase in the share of renewable sources in the energy balance of the country, the overall energy efficiency increases. Also, due to the introduction of Smart Grid, the growth rate of energy consumption decreases, caused by the growth of the economy and the increasing needs of the population.

The introduction of smart grids based on RESs is accompanied by a number of climatic, technological, economic, and other risks. For the most effective digitalization and intellectualization of the energy system, it is necessary to work on identifying and reducing these risks, that is, managing them.

The concept proposed by the authors for determining the most favorable regions for the introduction of intelligent grid systems based on RESs can become part of a comprehensive analysis of the regions before the implementation of such projects.

The variability of renewable energy generation is primarily associated with weather conditions, and therefore with climatic characteristics. Cluster analysis of climatic characteristics selected based on the analysis of existing studies will help to reduce climate risks at the initial stage of developing projects in the field of RESs, since the type of source will be selected most effectively by taking into account the environmental conditions.

\section{Acknowledgements}

The research is partially funded by the Ministry of Science and Higher Education of the Russian Federation under the strategic academic leadership program 'Priority 2030' (Agreement 075-15-2021-1333 dated 30.09.2021).

\section{References}

Abdelkareem, M.A., El Haj Assad, M., Sayed, E.T., Soudan, B., 2018. Recent Progress in the Use of Renewable Energy Sources to Power Water Desalination Plants. Desalination, Volume 435, pp. 97-113

Attia, T.M., 2019. The Challenges and Risks facing ICT in the Management and Operation of the Smart Grid. Renewable Energy and Sustainable Development, Volume 5(1), pp. 3-14

Baza, M., Nabil, M., Ismail, M., Mahmoud, M., Serpedin, E., Ashiqur Rahman, M., 2019. Blockchain-Based Charging Coordination Mechanism for Smart Grid Energy Storage Units. In: 2019 IEEE International Conference on Blockchain (Blockchain), pp. 504-509

Bugaeva, T., Filippova, I., Tribunskii, N., 2020. Applying the Analytic Hierarchy Process to Decision Making on the Development of Urban Energy System. In: Proceedings of the $2^{\text {nd }}$ International Scientific Conference on Innovations in Digital Economy: SPBPU IDE2020. pp. 1-6

Dorofeeva, L., Rodionov, D., Velichenkova, D., 2019. Infrastructure Potential of Creating "Smart Cities". In: Proceedings of the 2019 International SPBPU Scientific Conference on Innovations in Digital Economy. ACM, New York, NY, USA, pp. 1-7

Engeland, K., Borga, M., Creutin, J.-D., François, B., Ramos, M.-H., Vidal, J.-P., 2017. SpaceTime Variability of Climate Variables and Intermittent Renewable Electricity Production-A Review. Renewable and Sustainable Energy Reviews, Volume 79, pp. 600-617

Gasho, E.G., Kiseleva, A.I., Romanov, G.A., 2020. Hybrid Energy Systems based on Renewable Energy Sources in Various Climate Zones. Journal of Physics: Conference Series, Volume 1683, pp. 1-5

Guenther, M., 2018. Challenges of a 100\% Renewable Energy Supply in the Java-Bali Grid. International Journal of Technology, Volume 9(2), pp. 257-266 
Jebli, M.B., Farhani, S., Guesmi, K., 2020. Renewable Energy, $\mathrm{CO}_{2}$ Emissions and Value Added: Empirical Evidence from Countries with Different Income Levels. Structure Change and Economic Dynamics, Volume 53, pp. 402-410

Kalogirou, S., Mpiska, A., Giaoutzi, M., 2013. The ESPON 2013 Programme, p. 91

Khalid, R., Javaid, N., 2020. A Survey on Hyperparameters Optimization Algorithms of Forecasting Models in Smart Grid. Sustainable Cities and Society, Volume 61, 102275

Khalil, M., Berawi, M.A., Heryanto, R., Rizalie, A., 2019. Waste to Energy Technology: The Potential of Sustainable Biogas Production from Animal Waste in Indonesia. Renewable and Sustainable Energy Reviews, Volume 105, pp. 323-331

Kusrini, E., Kartohardjono, S., Sofyan, N., Yuwono, A.H., 2017. Innovation of Renewable Energy, $\mathrm{CO}_{2}$ Capture and Storage Materials for Better Applications. International Journal of Technology, Volume 8(8), pp. 1371-1375

Lui, U., Van, S., 2019. Innovative Transformation of Energy Networks (Smart Grid) in China: Problems and Prospects. New Economy, Business and Society, pp. 359-365

Lukyanchenko, S.A., 2017. Management Problems in Smart Grid Systems. Bulletins of Donetsk National Technical University, pp. 38-42

Mansouri, S.A., Ahmarinejad, A., Nematbakhsh, E., Javadi, M.S., Jordehi, A.R., Catalão, J.P.S., 2021. Energy Management in Microgrids Including Smart Homes: A Multi-Objective Approach. Sustainable Cities and Society, Volume 69, 102852

Nasledov, A., 2013. IBM SPSS Statistics 20 and AMOS: Professional Statistical Data Analysis. Питер

Olifirov, A.V., Makoveichuk, K.A., Petrenko, S.A., 2019. Integration of Cyber Security into the Smart Grid Operational Risk Management System. In: CEUR Workshop Proceedings. pp. 132-144

Ourahou, M., Ayrir, W., EL Hassouni, B., Haddi, A., 2020. Review on Smart Grid Control and Reliability in Presence of Renewable Energies: Challenges and Prospects. Mathematics and Computers in Simulation, Volume 167, pp. 19-31

Pereverzeva, K., Gutman, S., Petrov, K., Rytova, E., Shmatko, A., 2020. On Technology Readiness to Develop Wind Energy Sector in Russia. In: Proceedings of the $2^{\text {nd }}$ International Scientific Conference on Innovations in Digital Economy: SPBPU IDE2020. ACM, New York, NY, USA, pp. 1-8

Prakesh, S., Sherine, S., BIST, B., 2017. Forecasting Methodologies of Solar Resource and PV Power for Smart Grid Energy Management. International Journal of Pure and Applied Mathematics, Volume 116, pp. 313-318

Quan, H., Teo, J.K., Trivedi, A., Srinivasan, D., 2019. Optimal Energy Management of Vanadium Redox Flow Batteries Energy Storage System for Frequency Regulation and Peak Shaving in an Islanded Microgrid. In: 2019 IEEE Innovative Smart Grid Technologies-Asia (ISGT Asia). IEEE, pp. 4053-4058

Roques, F., Hiroux, C., Saguan, M., 2010. Optimal Wind Power Deployment in Europe-A Portfolio Approach. Energy Policy, Volume 38(7), pp. 3245-3256

Setiawan, E.A., Asvial, M., 2016. Renewable Energy's Role in a Changing World. International Journal of Technology, Volume 7(8), pp. 1280-1282

Tishkov, S., Shcherbak, A., Karginova-Gubinova, V., Volkov, A., Tleppayev, A., Pakhomova, A., 2020. Assessment the Role of Renewable Energy in Socio-Economic Development of Rural and Arctic Regions. Entrepreneurship and Sustainability Issues, Volume 7, pp. 3354-3368

Worighi, I., Maach, A., Hafid, A., Hegazy, O., Van Mierlo, J., 2019. Integrating Renewable Energy in Smart Grid System: Architecture, Virtualization and Analysis. Sustainable Energy, Grids and Networks, Volume 18, 100226 